\title{
Audrey Duru, Essais de soi. Poésie spirituelle et rapport à soi, entre Montaigne et Descartes
}

Genève, Droz, coll. « Travaux d'Humanisme et Renaissance », 2012, 509 p.

Daniel Vidal

\section{(2) OpenEdition}

\section{Journals}

Édition électronique

URL : http://journals.openedition.org/assr/25467

DOI : $10.4000 /$ assr. 25467

ISSN : $1777-5825$

Éditeur

Éditions de l'EHESS

Édition imprimée

Date de publication : 30 décembre 2013

Pagination : 185

ISSN : 0335-5985

Référence électronique

Daniel Vidal, « Audrey Duru, Essais de soi. Poésie spirituelle et rapport à soi, entre Montaigne et Descartes », Archives de sciences sociales des religions [En ligne], 164 | 2013, mis en ligne le 21 février 2014, consulté le 10 décembre 2020. URL : http://journals.openedition.org/assr/25467 ; DOI : https:// doi.org/10.4000/assr.25467

Ce document a été généré automatiquement le 10 décembre 2020.

(c) Archives de sciences sociales des religions 


\section{Audrey Duru, Essais de soi. Poésie spirituelle et rapport à soi, entre Montaigne et Descartes}

Genève, Droz, coll. « Travaux d'Humanisme et Renaissance », 2012, 509 p.

Daniel Vidal

\section{RÉFÉRENCE}

Audrey Duru, Essais de soi. Poésie spirituelle et rapport à soi, entre Montaigne et Descartes, Genève, Droz, coll. « Travaux d'Humanisme et Renaissance », 2012, 509 p. 
$1 \mathrm{Au}$ principe même de la mystique, accomplissement le plus radical de la spiritualité occidentale, les travaux de Michel de Certeau ont posé avec force la question du sujet, celui qui dit volo dans le temps même où il s'engage dans l'impossible quête de son dieu. Paradigme fondateur qui consacre le régime de la subjectivité comme opérateur décisif de l'événement mystique. Aux frontières de celui-ci, mais en son champ de gravitation, la poésie spirituelle des années 1580-1640 - dont les auteurs sont des laïcs de mouvance réformée ou catholique - invite à une réflexion approfondie sur le statut du sujet de l'écriture et de son énonciation. Entre les Essais de Montaigne, dont la figure centrale est l'individu en ses «singularités accidentelles », et le « je » du Discours de la méthode et des Méditations métaphysiques de Descartes qui (se) pense comme sujet du cogito, Audrey Duru analyse le « rapport à soi » qui sous-tend l'écriture de ces poèmes, et les «figures de la subjectivité » qu'ils proposent. D'emblée, l'auteur, dans cet ouvrage en tous points d'une rigueur et d'une richesse remarquables, définit le "rapport à soi " comme s'instituant sur la ruine du « moi », loin donc de toute valeur dont la créature ferait son héritage en propre. Mais ce rapport « s'accomplit en accédant à l'altérité au plus intime de soi ». Le « je », le « dire je », qui organisent l'écriture poétique de cette génération d'auteurs spirituels, sont ainsi interrogés au plus près de leur capacité à « inventer ", à proprement parler, une modalité de sujet qui se distingue de la notion d'individu, sans encore valoir comme sujet autofondé par sa raison même. Nulle référence évolutionniste ici : mais la proposition d'un champ épistémologique assez singulier et maîtrisé pour participer de cette « sécularisation du christianisme » qui signe en effet le destin paradoxal de la spiritualité.

2 Il reste que "l'élaboration de la subjectivité » dans la poésie chrétienne ne relève pas d'une seule et même écriture et chaque « auteur » d'un seul et même statut dans le direje qui le qualifie. Si la référence au je, précise A. Duru, «n'est pas pensée comme concept », il faut donc en " problématiser » les configurations. Le rapport à soi se joue dans un ensemble de relations qui se tissent entre le "je » énonciateur, le «je » locuteur, le "je » support de l'expérience de soi-même, et qui fondent «les enjeux individuels et collectifs » de «l'exercice de subjectivation ». C'est de ce vaste réseau de polarités que l'écriture de ces poèmes a charge de maintenir la tension. Et cela ne se peut que si cette écriture-là, qu'elle soit d'extase ou d'humilité, de pénitence ou de triomphe, est tension pure. L'auteur désigne ici une exigence propre à la poétique spirituelle, et commune aux auteurs aussi différents que A. Mage de Fiefmelin le Réformé, Pierre de Croix le mystique, et Claude Hopil le poète du pur amour. Si, note Audrey Duru, « en contexte social, le rapport à soi est toujours singulier » et participe toujours d'un ancrage historique, ce qui qualifie l'ensemble de cette production poétique est le statut commun de la langue. Telle poésie est en effet acte de langage, discours spirituel performatif à la première personne du singulier, et protestation d'une parole qui va de l'élancement lyrique le plus accompli à la projection d'un cri ou 
d'un gémissement en leur nudité même, cette « extase blanche » qu'avait ainsi nommée Michèle Clément. La poésie spirituelle, en cette génération à la charnière des $\mathrm{XVI}^{\mathrm{e}}$ et $\mathrm{xvII}^{\mathrm{e}}$ siècles, multiplie les signes, les images, les symboles, bref, le registre infini des signifiants, et mobilise cette abondance pour signifier " un secret », pour « énoncer une énigme ». Car telle «mise en scène de l'interprétation » n'a pas pour effet de délivrer un moment de vérité, de dévoilement, mais, au contraire - et cela est capital pour l'intelligence de ce qui se joue dans le déploiement de la subjectivité - de produire un mystère. Interprétation "déceptive ", note A. Duru, "qui suggère un mystère généralisé ». Mais si Dieu, en effet, ne peut se dire, qu'en est-il du «je » qui dit cet indicible?

La poésie d'André Mage (L'Image d'un Mage ou Le Spirituel d'A. Mage, 1601) témoigne sans doute de l'expérience la plus aboutie d'une abondance d'images portant le langage «à la limite de ses capacités de représentation ", par quoi ce qui est désigné dans cette écriture poétique, n'est plus en effet «ni Dieu ni l'être, [mais] le mécanisme même d'abolition du signe » : les signes sont portés à insignifiance par leur abondance même. Plus encore : ils « dénotent l'absence d'être » - «l'absence de Dieu ». L'auteur rappelle opportunément que Calvin récusait "l'existence d'un lien entre signe et référent». Aussi bien l'acte poétique de Mage se fonde-t-il sur ce paradoxe, de "laisser l'être innommé » dans le mouvement même qui mobilise un foisonnement de signes. La « rage se signifier » se déploie en énigme. Car l'abondance rhétorique ne tend pas à dire la «plénitude » du divin, mais au contraire «l'inconsistance, l'éphémère » du monde, qui ne peut accéder à une pure diction de Dieu. Pour le poète Réformé, selon l'heureuse expression d'Audrey Duru, « les symboles de l'évanescence indiquent l'évanescence du symbole ». La parole poétique de Mage porte effacement de la représentation de Dieu. Qu'en est-il alors du poème ? Il est " écriture de soi », et par cette écriture, cette parole intime, par « la puissance et la nécessité » de cet acte locutoire, le je apparaît comme la seule issue désirable par quoi le divin se nomme. Mage paraphrase les Psaumes, «l'un des hypertextes majeurs des poèmes chrétiens ». Soumission au Texte? Poème de la servitude volontaire? Non : "apprentissage d'une forme de liberté », propose A. Duru, dans cette parole poétique tout entière assumée comme vérité du je lui-même. Parole qui dit la pénitence comme sa propre dégradation - cri, on l'a vu, et plainte. Le psaume de pénitence se réduit ainsi à "l'acte illocutoire», et son écriture est "poésie de l'impossible poésie ». Subversion de la poésie. Cette parole qui se fait cri «sous-tend un vouloir-dire ». Plus est radicale la mise en crise de la parole, plus elle témoigne d'une expérience singulière de Dieu. Plus elle est "parole personnelle». Le "je», selon A. Duru, est alors cela même : la personne. Non quelque sujet autonome et autofondé, mais celui-là qui, dans la pénitence, cette " adresse individuelle et ordinaire à Dieu », se livre et s'assume comme "figure juridique en situation d'aveu». Ce que dit ici le poème, c'est qu'il n'est de «sujet» qui ne soit coupable. Le «moi » est haïssable, écrivait Pascal. «Le $j$ moy e plaide coupable », dit Mage héritier du premier âge de la Réforme. Le je est la faute.

4 En ce discours à la première personne, le poème spirituel devient cette "parole absolue » qui est en même temps, et par là-même, discours de l'expérience subjective. À l'inverse de Mage, Pierre de Croix, en son Miroir de l'amour divin (1608), ne nie pas la capacité du symbole à signifier Dieu, quand même Dieu, acte pur et omniscient, excède toute représentation. L'abondance des signes «disent le Tout de Dieu et le Rien du monde», "le rien du je». L'anéantissement "vaut» déification. Comme «signe 
insignifiant ", je est, à proprement parler, selon l'auteur, « absent du poème ». Comme il l'est, à cet égard, de la mystique du pur amour, où, tout moi et amour-propre forclos, le sujet peut enfin se dire comme «déifié ». Sujet éthique, propose l'auteur, dont la parole personnelle "construit une intériorité", ce retour sur soi dont la poésie spirituelle est la langue d'exception. Là, en ce verbe performatif seul capable, par la puissance du désir qui s'y énonce, de dire l'en moy, la volonté humaine et la volonté divine entrent en concordance. L'une est l'autre aussi bien, «Dieu davantage en moi que moi-même ", et moi pleinement inscrit en mon dieu. L'en moy est ainsi ce point fixe, ce centre de gravité où s'opèrent «la dépossession du soi par la plus totale extériorité », et « la plus intime découverte de l'intériorité ». La notion de personne est alors requise pour énoncer cette neuve figure du sujet avant le cogito. La personne, ce « paradoxe absolu » qu'analyse Emmanuel Housset (La vocation de la personne, 2007), « ce qu'il y a de plus universel et de plus individué ».

De l'abondance des images à l'ascèse de l'énoncé, Claude Hopil, poète du pur amour, traverse toute l'épaisseur du langage pour produire une « locution pure », proche d'une ligne musicale comme il en irait d'une " communication angélique ». Du pur amour qui s'énonce comme tension entre anéantissement de soi et absence de Dieu, Les Divins eslancemens d'amour ou Les doux vols de l'ame sont le témoignage le plus éclairant. Ils participent du désir de fonder une communication idéale «qui serait abstraite des signes ", confirmant la singularité de la poésie spirituelle d'être cette lutte incessante contre les signifiants, qui «recouvrent l'être", loin de le dévoiler. C'est en cette critique radicale du langage que s'entend le sujet en son écriture. Ce qu'Audrey Duru appelle une "subjectivité énonciative », ou "subjectivité impersonnelle » et que, dans son ouvrage Théologies poétiques de l'âge baroque - La Muse chrétienne (2006, cf. ASSR, 138), Christophe Bourgeois identifie au principe de l'« excès de silence " par saturation et exténuation des verbes, chez Hopil, ou de ce que Pierre de Croix nomme " conceps", ces éclats poétiques seuls capables de " représenter » les passions. Cette subjectivité est revendiquée par Hopil, en son statut de poète lettré et parlant « de soi » : «Je n'ai pas, à vray dire, exposé les paroles des Cantiques, mais je me suis seulement expliqué moymesme par les paroles des Cantiques». Peut-on aller jusqu'à dire, comme le propose l'auteur, que le je de Hopil est ici «anonyme »? Peut-être, si l'on entend par là qu'il définit un statut de locuteur valant pour tout autre en même travail d'écriture spirituelle et semblablement "abstrait des accidents historiques et individuels". Distinction "subtile», convient cependant l'auteur. Il reste que ce "discours de la personne " introduit à l'expérience spécifique et singulière de la dévotion à Dieu. Et telle expérience s'établit au plus profond d'un "espace intérieur" - espace de la « subjectivité »- où, selon la formule de l'auteur, « le je accède à lui-même » en même temps qu'il s'engendre d'un «monde intérieur obscur». Si Audrey Duru précise bien qu'il n'est pas ici question de glisser vers une théorie de l'Inconscient, du moins est-on assuré que la poésie spirituelle, par l'éradication du «moi», la mise en échec de la symbolisation, et, notamment chez Hopil, par la référence à la théologie négative, participe de l'institution du sujet comme capacité à " maitriser le soi », ce désordre du monde, et " accueillir la grâce », ce don gratuit d'altérité. 